\title{
Correlates of Job Stress among University Lecturers in Rivers State
}

\author{
Izuchi Mary-Rose N. PhD, Onukwufor Jonathan N. PhD \\ Department of Educational Psychology, Guidance \& Counseling, Faculty of Education, University of Port \\ Harcourt
}

*Corresponding Author: Izuchi Mary-Rose N. PhD, Department of Educational Psychology, Guidance \& Counseling, Faculty of Education, University of Port Harcourt

\begin{abstract}
The study investigated the correlates of job stress among university lecturers in Rivers State. Correlational design was adopted for the study. A sample of 208 university lecturers was drawn through proportional stratified random sampling technique from a population of 308 lecturers in the faculties of education of the three universities used for the study. Two research questions and two null hypotheses guided the study. The instruments for data collection were Correlates of Job Stress Questionnaire (coded CJSQ) and Job Stress Questionnaire (JSQ) made up of 24 and 21 items respectively. The instruments were validated by experts in Educational Psychology Guidance and Counselling, Measurement and Evaluation. The reliability coefficients of 0.78 and .080 were established using Cronbach alpha technique. Multiple regression and beta value were used to answer the research questions while analysis of variance (ANOVA) and t-test were used to test the hypotheses at 0.05 alpha level. The result of the study reveals that workload, insufficient facilities and over population of students jointly, independently and significantly relate to university lecturers' job stress. The researchers recommend that lecturers should develop coping strategies and the university administration should adopt practices that will help to alleviate job stress among university lecturers' to enable them contribute to the human resources and technological needs of the nation among others.
\end{abstract}

Keywords: Job stress, Lecturer, University, Workload, Insufficient facilities, Overpopulation.

\section{INTRODUCTION}

Lecturers in various institutions of higher learning especially universities seem to be undergoing, a lot of job stress which invariably impact on their health and job performance. Stress according to Uzonwanne (2014) is the adverse reaction people have to excessive pressure or other types of undesirable, mental, physical, emotional, social or environmental demands placed on them. Stress is an inevitable and unavoidable component of life due to complexities and competitiveness in living standards (Sindhu, 2014). Sindhu (2014) was of the opinion that in modern times stress in general and job stress in particular has become a part of life and has received considerable attention in recent years.

A stressful individual is loaded with tension and worry, one in a bid to meet up with the demands of work or challenges is stressed up. Every individual experiences stress and no profession is stress free. Stress can be detrimental to individuals as it interferes with their general well being.

Job is connected to the world of work. Job, occupation, profession, vocation, work and career can be used interchangeably. They all have to do with what one does to earn a living. Job stress therefore are those stressors associated with job performance at all levels including universities. Job performance according to Fred (2017) is the extent to which members of a particular profession achieve the desired results by performing the duties and roles ascribed to them in their places of work. Furthermore stress that is intrinsic or otherwise related to job or the organization is referred to as job or occupational stress (Okorie-Uguru, 2007).

Job stress can be in the area of workload, insufficient facilities and over population of students lecturers may be assigned to teach many courses and supervise many students' projects/theses at undergraduate and graduate levels as well as attend to other administrative and statutory meetings. In addition to these, lecturers in the universities attend seminars; workshops write and present papers in professional conferences. All these take their toll on the lecturers. Omoniyi (2013) opined that in 
recent times work load of academics have increased and they are under increased pressure to attract external funds for their research and to either 'publish or perish'.

Akinade (2008) in his work said that Nigerians are working harder and longer hours in which lecturing is a part. Teachers including lecturers have been identified as an occupational group that functions under high stress. United Kingdom Health and Safety Executive cited in Damilola (2013) reported that two out of every five teachers were highly stressed as against one in every five in the other occupations such as nursing, security, management, and so on.

Insufficient facilities seem to be another contributory factor to lecturers job stress. It has been observed that lecturers in some universities lack good office accommodation. Fans and air conditioners are lacking in their offices. Even if these facilities are available, there is poor electricity supply. Conveniences in some universities are nothing to write home about. There is no steady water supply to keep the conveniences clean. In most classrooms and lecture halls, inadequate supply of podium and public address system abound. All these can contribute to lecturers deviating from normal functioning. There seems to be growing evidence that there are really no private, states or federal owned universities that will genuinely claim to enjoy basic facilities and resources (Omoniyi, 2013).

Over population of students seems to also contribute to lecturers' job stress. In some faculties in the universities there abound over-congested classrooms. Lecturers strain their voices for students to hear them, when public address system is unavailable. Long working hours are spent by lecturers, both on and off campus marking and computing results of students thereby seriously compromising the learning environment. Overpopulation of students can reduce efficiency of lecturers and impinge on their health.

The researchers observed that learning environment in Nigerian universities is not conducive as a result of congested classroom. Omoniyi (2013) also observed that learning environment in Nigerian universities is seriously compromised by over-congested classrooms and laboratories. It is difficult for lecturers to efficiently manage excessive workload, inadequate facilities and overpopulation of students without much stress. It is against this back drop that the researchers intend to ascertain the correlates of job stress among university lecturers in Rivers State.

In specific terms the study intends to do the following.

- Find out the extent workload, insufficient facilities and overpopulation of students jointly relate with university lecturers' job stress.

- To find out the extent workload, insufficient facilities and overpopulation of students separately relate with university lecturers' job stress.

The following research questions guided the study.

- To what extent do workload, insufficient facilities and overpopulation of students jointly relate with university lecturers' job stress?

- To what extent do workload, insufficient facilities and overpopulation of students separately relate with university lecturers job stress?

The following null hypotheses formulated and tested at 0.05 alpha level of significance guided the study.

- Workload, insufficient facilities and overpopulation of students do not jointly significantly relate with university lecturers' job stress.

- Workload, insufficient facilities and overpopulation of students do not independently significantly relate with university lecturers' job stress.

\section{METHOD}

The study adopted correlational design because the researchers are interested in finding out whether there is a relationship between two or more variables of the study. Nwankwo (2016) stated that correlational type of relationship studies involves finding out whether there is any relationship between two or more variables by correlating the scores from the variables involved. This design is therefore very appropriate for the study. The population of the study was all the lecturers in the faculties of education in Rivers State universities. As at the time of the study, the population of the respondents was 308 lecturers involving 170, 85 and 53 from University of Port Harcourt, Ignatius 
Ajuru University of Education and Rivers State University respectively. (Faculty Officers, 2017). A sample of 208 lecturers was drawn from the population through proportionate stratified random sampling technique made up of 115,57 and 36 lecturers. The instruments for data collection were Correlates of Job Stress Questionnaire Coded (CJSQ) and Job Stress Questionnaire (JSQ). The instruments were developed by the researchers. The CJSQ has two sections, A and B. Section A sought information on personal data while section B sought information on correlates of job stress among university lecturers. Section B had three subsections namely workload, insufficient facilities and overpopulation of students which contained ten (10) items, eight (8) items and six (6) items totaling 24 items in all. The second instrument (JSQ) contained 21 items on job stress. The lecturers were asked to respond to each of the items on a four point scale of Strongly Agree (SA), Agree (A), Disagree (D) and Strongly Disagree (SD) which weighted 4, 3, 2 and 1 respectively.

The instruments were validated by three experts in Educational Psychology, Guidance and Counseling, Measurement and Evaluation. The reliability of the instruments (CJSQ and JSQ) were determined using Cronbach Alpha statistical technique for internal consistencies of the instruments. Their reliability co-efficient were found to be 0.78 and 0.80 . Multiple regression and beta value were used to answer the research questions while analysis of variance (ANOVA) associated with regression and t-test were used to test the hypotheses at 0.05 alpha level.

\section{Results}

Research Question 1: To what extent do workload, insufficient facilities, over population of students jointly relate with job stress among university lecturers?

Hypothesis 1: Workload, insufficient facilities, over population of students do not jointly significantly relate with job stress among university lecturers.

Table1. Multiple regression analysis of joint relationship of workload, insufficient facilities, overpopulation of students and university lecturers job stress.

\begin{tabular}{|c|c|c|c|c|c|}
\hline Model & $\mathbf{R}$ & $\mathbf{R}^{2}$ & Adjusted $\mathbf{R}^{2}$ & \multicolumn{2}{|c|}{ Std. Error of Estimate } \\
\hline & .452 & .204 & .193 & \multicolumn{2}{|c|}{6.388} \\
\hline \multicolumn{6}{|c|}{ Analysis of Variance (ANOVA) } \\
\hline & Sum of Squares & df & Mean Square & $\mathbf{F}$ & Sig \\
\hline Regression & 2139.058 & 3 & 713.019 & 17.474 & .000 \\
\hline Residual & 8324.206 & 204 & 40.805 & & \\
\hline Total & 10463.264 & 207 & & & \\
\hline
\end{tabular}

Table 1 shows that the multiple regression yielded a coefficient of $.452, \mathrm{R}^{2}$ of .204 , adjusted $\mathrm{R}^{2}$ of .193 and standard error of the estimate of 6.388 . Based on the $\mathrm{R}^{2}$ value, it is seen that workload, insufficient facilities and over population of students jointly relate about $20.4 \%$ to university lecturers' job stress.

However, to determine if the relationship is significant or not, analysis of variance (ANOVA) associated with the multiple regression was employed. The calculated F-value of 17.474 was significant at .000 which is less than the chosen alpha level of $0.05(\mathrm{p}<0.05)$. Hence, the null hypothesis is rejected indicating that workload, insufficient facilities and over population of students jointly significantly relate with university lecturers' job stress.

Research Question 2: To what extent do workload, insufficient facilities, over population of students independently relate with job stress among university lecturers?

Hypothesis 2: Workload, insufficient facilities, over population of students do not independently significantly relate with job stress among university lecturers.

Table2. Relative contribution of workload, insufficient facilities, over population of students to university lecturers' job stress.

\begin{tabular}{|c|c|c|c|c|c|}
\hline \multirow[t]{2}{*}{ Model } & \multicolumn{2}{|c|}{ Unstandardized Coefficients } & \multirow{2}{*}{$\begin{array}{c}\text { Standardized Coefficients } \\
\text { Beta }\end{array}$} & \multirow[t]{2}{*}{$\mathbf{t}$} & \multirow[t]{2}{*}{ Sign } \\
\hline & B & Std Error & & & \\
\hline Job stress (constant) & 21.552 & 6.806 & & 3.167 & .002 \\
\hline Workload & .505 & .171 & 201 & 2.961 & .003 \\
\hline Insufficient facilities & .593 & .133 & 295 & 4.459 & .000 \\
\hline Over population of stds & .492 & 210 & .166 & 2.340 & .020 \\
\hline
\end{tabular}


Table 2 reveals that the beta value of .201 for workload which was significant based on its t value of 2.961 was significant at .003 which is less than the chosen probability level of $0.05(\mathrm{p}<0.05)$. The beta value of .295 for insufficient facilities which was significant based on its t-value of 4.459 was significant at .000 which is less than the chosen probability level of $0.05(\mathrm{p}<0.05)$. Also the beta value of .166 for over population of students which was significant based on its t-value of 2.340 was significant at 0.20 which is less than the chosen probability level of $0.05(\mathrm{p}<0.05)$. Based on the beta values, one can deduce that insufficient facilities contributed highest, followed by workload and lastly over population of students to university lecturers job stress. Hence, based on the t-values, the null hypothesis is rejected indicating that workload, insufficient facilities and over population of students independently significantly relate with university lecturers' job stress.

\section{DISCUSSION OF FINDINGS}

One of the findings of the study showed that workload, insufficient facilities and over population of students jointly significantly relate to university lecturer's job stress. This was revealed by the multiple regressions in table 2 which yield a coefficient of $.452, \mathrm{R}^{2}$ of .204 , adjusted $\mathrm{R}^{2}$ of .193 and standard error of the estimate of 6.388. Based on the $\mathrm{R}^{2}$ value it is seen that the independent variables of the study jointly relate about $20.4 \%$ to university lecturers' job stress. Also Analysis of Variance (ANOVA) associated with the multiple regression was employed to determine if the relationship is significant or not. The calculated F-value of 17.474 was significant at .000 which is less than the chosen alpha level of 0.05 ( $\mathrm{p}<0.05$ ). The reason for this outcome is not far fetched because these lecturers are found in similar work environment. This result is in agreement with the finding of Byrne \& Hall in Salami (2013) that work overload is one of the organizational factors that contributed to teachers stress and burnout. The work of Omoniyi (2013) in the area of basic facilities and over population of students also supports this finding.

Furthermore, the independent variables of the study (workload, insufficient facilities and over population of students) significantly relate to university lecturers' job stress separately. Table 2 reveals that their beta values of $.201, .295$ and .166 were significant based on their t-values of 2.961, 4.459 and 2.340 respectively. Their significant levels are all less than the chosen probability level of 0.05 ( $\mathrm{p}<0.05$ ) (see Table 2, p.6). Based on the beta values it is deduced that insufficient facilities contributes highest followed by workload and lastly over population of students to university lecturers' job stress. The hypothesis is rejected based on the t-values indicating that workload, insufficient facilities and overpopulation of students independently significantly relate with university lecturers' job stress. This result is not surprising to the researchers because of negative comments often made by university lecturers concerning job stress. However, the result is supported by the finding of Damilola (2013) who found that there is no difference in stress experienced by lecturers in different faculties of the university. The above results uphold the findings of Khan, Yusoff and Azam (2014) that both internal as well as external factors contributed towards the development of job stress among university teachers in Pakistan. This result means that among the correlates of job stress, insufficient facilities are the highest stressors to the university lecturers.

\section{CONCLUSION}

In the light of the findings of this study, it was concluded that workload, insufficient facilities and over population of students relate jointly significantly and independently significantly with university lecturers job stress with insufficient facilities contributing highest in separate significant relationship.

\section{RECOMMENDATIONS}

Based on the findings of the study the following recommendations were made by the researchers.

- Since job stress is inevitable for university lecturers, they should develop coping strategies to manage the situation. Lecturers should accept the reality of the situation and have a positive mind set towards it and focus on the prospects of the job.

- The university administration should adopt practices that will help to alleviate stress among university lecturers. This can be done by establishing recreation centers such as staff common room, staff club and fitness centers among others.

- Functional well equipped counseling centers should be established in universities for professional guidance counselors to render help to the lecturers. 
- The federal government should live up to expectation by providing fund for revitalization of universities especially in the area of infrastructure.

\section{REFERENCES}

[1] Akinade, E.A. (2008). Stress: Understanding and Managing it. Lagos: Pumark Publishers.

[2] Damilola, R.A. (2013). Occupational stress among academic staff of Ekiti State University, Ado-Ekiti. European Scientific Journal, 9(4), 202-208.

[3] Fred, E.O. (2017) Personality traits as predictors of guidance counsellors' job performance in Bayelsa State. Unpublished Masters Thesis, University of Port Harcourt.

[4] Khan, A., Yusof, R.B.M. \& Azam, K. (2014). Factors of job stress among university teachers in Pakistan. Journal of Management Info, 2(1) 62-67.

[5] Nwankwo, O.C. (2016). A practical guide to research writing. Port Harcourt: M\&J Grand Orbit and Communication Ltd.

[6] Okorie-Uguru, D.C. (2007). Reading in psychology series. Lagos: Graams.

[7] Omoniyi, M.B.I. (2013). Sources of work place stressors among university lecturers in South West Nigeria: Implications for counseling. First annual international interdisciplinary conference: AIIC 2013, 24-26 April, Azons. Portugal-Proceedings.

[8] Salami, S.O. (2011). Job stress and burn out among lecturers: Personality and social support as moderators. Asian Social Science, 7(5) 110-118.

[9] Sindhu, K.P. (2014). A study on stressors among college teachers. Journal of Business and Management, 16(7) $37-41$.

[10] Uzonwanne, F.C. (2014). Depression anxiety and stress as correlates of organizational behaviour among oil workers in Nigeria. European Journal of Globalization and Development Research, 10(1) 619-637.

Citation: Izuchi Mary-Rose N. PhD. " Correlates of Job Stress among University Lecturers in Rivers State " International Journal of Humanities Social Sciences and Education (IJHSSE), vol 4, no. 12, 2017, pp. 48-52. doi: http://dx.doi.org/10.20431/2349-0381.0412006.

Copyright: () 2017 Authors. This is an open-access article distributed under the terms of the Creative Commons Attribution License, which permits unrestricted use, distribution, and reproduction in any medium, provided the original author and source are credited. 